\title{
Analisis TeKs WaCANA Istima': \\ Tinjauan Teori Inovatif Transformatif Terhadap \\ Surat Al-WaQI'Ah Ayat 77-79
}

\author{
Slamet Daroini \\ Dosen Fakultas Humaniora dan Budaya Universitas Islam Negeri (UIN) Malang
}

\begin{abstract}
Language consists of words organized based on grammar (Al-Qawaid alLughowiyyah) to construct sentences and of sound system representing specific meaning. Listening comprehension (Al-Maharah al Istima') is a skill in analyzing Arabic speech sounds to understand the text messages. Therefore, in practice it does not only need an understanding of textual meaning that refers to dictionary meaning (lexical meaning) or grammatical meaning, but also should take into account the linguistic aspects, that is, grammar (Nahwu and Sharf) and semantic unit (Ashwat). Considering the phenomena, the writer wants to discuss the problems based on Chomsky's theory of Innovative-Transformative Grammar. The data supported this analysis are from Surah Al-Waqi'ah 77-79. The result of analysis is expected to prove the truth of the existing assumption.
\end{abstract}

Keywords: inovatif, transformatif

\section{A. Pendahuluan}

Dalam pengajaran Bahasa Arab dikenal dengan 4 (empat) ketrampilan kebahasan yang harus dimiliki oleh peserta didik yaitu; Al-maharah al-Kalam wa al-Hadits (Ketrampilan Berbicara dan Bercakap), Al-maharah al-Qira'ah (Ketrampilan Membaca), Al-maharah al-Istima' (Ketrampilan Mendengar), dan Al-maharah al-Kitabah (Ketrampilan Menulis). Hal ini senada dengan pengajaran bahasa Arab di Program Khusus Pembelajaran Bahasa Arab (PKPBA) di Universitas Islam Negeri (UIN) Malang. 
Dalam penguasaan 4 (empat) ketrampilan kebahasaan tersebut , sebagian ahli bahasa berasumsi bahwa kemampuan kebahasaan seseorang hanya ditentukan oleh tingkat penguasaan terhadap tata bahasa Arab, yang mana pendapat ini lebih didasarkan pada al-Nahwu dan al-Sharf, sebagian yang lain menolak pendapat tersebut dan mengatakan bahwa tingkat kemampuan kebahasaan seseorang dipengaruhi oleh penguasaan seseorang terhadap arti kosa kata (Ma'na al-Mufradat), pendapat ini lebih didasarkan pada pengusaan kamus (Makna leksikal).

Berdasarkan fenomena yang ada, maka penulis berkeinginan_dengan tulisan ini- untuk memaparkan permasalahan yang terjadi yang didasarkan pada teori kebahasaan ( analisa teks menurut teori Inovatif Transformatif oleh Chomsky) dan didukung dengan sampel pada surat al-Waqi'ah ayat 77-79). Serta sekaligus-dengan tulisan ini-penulis ingin membuktikan tingkat kebenaran atas asumsi yang ada.

\section{B. Sekilas Pandang A1-Maharah Al-Istima'}

Kemampuan individu dalam menangkap isi pesan dari reks bahasa menyimak (mendengar/istima') dipengaruhi oleh 3 (tiga) aspek. Ketiganya merupakan aspek penting yang harus dimiliki oleh individu. Sehinggga dapat menangkap isi pesan teks secara sempurna. Ketrampilan Istima' (mendengar) merupakan kecakapan menganalisa simbol-simbol dari bunyi bahasa sehingga bisa sampai pada makna sebenarnya (nafsi al-makna) dari ujaran yang disampaikan oleh pengujar bahasa tanpa ada tambahan, pengurangan, dan penyelewengan makna (Abdul Madjid Sholah, 1981, 65).

Ketrampilan Istima' (mendengar) merupakan ketrampilan kebahasaan yang sering dipergunakan oleh individu dalam memperoleh informasi, ilmu pengetahuan dan lain sebagainya, sebagaimana yang diungkapkan harakah, mustofa,1998, hal. 147 bahwa berdasarkan penelitian terhadap siswa sekolah tingkat menengah di AS terbukti bahwa 30\% waktu/hari dipergunakan untuk berbicara dan bercakap-cakap, 16\% waktu/hari untuk membaca, $9 \%$ waktu/hari untuk menulis, dan $45 \%$ waktu/hari untuk mendengar (istima'). 
Dalam pembelajarannya ketrampilan mendengar (istima') bertujuan untuk membekali peserta didik dalam kecakapan, latihan-latihan, kemampuan membedakan bunyi bahasa. Maka secara khusus dapat dilihat dalam tujuan pembelajaran istima'. Menurut Madkur Ahmad bahwa tujuan pembelajaran istima' yang paling penting adalah sebagai point-point berikut: (a) Siswa mampu mengetahui tujuan pembicaran, (b) Siswa mampu mengetahui tema pembicaraan dan pokok-pokok pikiran utaman dari sebuah pembicaraan, (c) Siswa mampu menemukan pikiran-pikiran parsial (juziyah), mampu menemukan inti kalimat setiap paragrap dengan mempertimbangkan urutan pembicaraan sesuai dengan tema utama dan pokok pikiran utama, (d) Siswa mampu menganalisa pokok pikiran dan menginterpretasikan, maka hal tersebut dapat disimpulkan sebagai berikut: Pengalaman sebelumnya, tujuan pembicara, membedakan antara yang realitas dan idealitas, mampu membedakan antara hal yang primer dan skunder dalam pembicaraan, mampu mengevaluasi pembicaraan, dan mampu mengikuti pembicaraan yang cepat. (Madkur, Ahmad 1984, hal.68-69).

Mengenai tahapan-tahapan pembelajaran ketrampilan mendengar dibedakan menjadi 3 (tiga) tahap yaitu: Tahap pertama, Persiapan (Marhalah I'dad), maka materi Istima' harus dipersiapkan sebelumnya, dipilih dengar mempertimbangkan kemampuan, kebutuhan, perhatian siswa, dan persiapan tentang sarana dan prasana pengajaran yang baik, Tahap kedua, Pelaksanaan pada pembelajarannya pendidik mengarahkan peserta didiknya kearah pointpoint yang terdapat dalam tema dan mengingatkan kembali tentang namanama dan angka-angka yang telah terlupakan, dan memberikan waktu untuk tanya jawab, serta memberikan arahan-arahan yang bisa membantu dalam proses mendengarkan teks yang akan disampaikan, Tahap ketiga, tindak lanjut, yaitu diskusi antara pendidik dan peserta didik, dan pendidik menenyakan tentang materi untuk mengetahui sejauh mana pencapaian tujuan serta evaluasi atas kesalahan yang terjadi. 


\section{Istima' Tinjauan Teori Inovatif Transformatif}

\section{(1) Istima' Tinjauan Tata Bahasa (Nahwu dan Sharf/النحـو و الصـرف)}

Dalam pembahasannya lebih berorientasi pada sisi kedudukan kalimat (jenis kata / mufradat / jumlah) yang dimulai dari pembahsan tentang pembagian kata isim, fi'il, dan harf, walaupun didalamnya banyak dijumpai perbedaan -perbedaan diantara pakar nahwu dan sharf yang diantaranya adalah kelompok Khuffah dan kelompok basrah ditambah dengan kelompok pebaharu dalam nahwu yaitu dengan munculnya pandangan tentang Tajdidu al nahwi. Ruang lingkup kajian nahwu menurut Syauqy Dhoif, 1986, hal. 66-75 terdapat 5 (lima) hal yaitu: Pertama, suku kata (kalimat) dan cara pelafalannya serta bentuk-bentuk fi'il (kata kerja) dan harf (huruf). Kedua, pemaparan pembagian isim (kata benda) dan macammacamnya. Ketiga, pemaparan tentang marfu'at ( kata-kata yang dibaca rafa'). Keempat, pemaparan tentang manshubat (kata-kata yang dibaca nasab). Kelima, pemaparan tentang pelengkap (Takmulat) yang antara lain adalah bentuk-bentuk fi'il madly, mudlari', ketentuan waktu serta hal-hal yang menasabkan dan menjazamkan fi'il.

Adapun kecakapan yang diharapkan dari tata Bahasa Arab (Nahur) menurut Chomsky mencakup pada 3 (tiga) kemampuan dasar yaitu;

(a) Kemampuan Analisis, maka pada tataran idealnya konsep nahwu ini merupakan konsep yang toleran yaitu dengan memaparkan aturanaturan yang jelas sehingga mampu melahirkan ungkapan-ungkapan yang tidak terbatas didalam bahasa tertentu dan tidak menghasilkan ungkapan yang tidak beraturan.

(b) Kemampuan Diskripsi, maka pada tataran idealnya konsep nahwu ini merupakan konsep yang doktrin yaitu dengan memaparkan aturanaturan bentuk diskriptis , ungkapan-ungkapan yang benar menurut aturan yang ada

(c) Kemampuan Interpretasi, seharusnya nahwu mengkhususkan aturanaturannya dengan bentuk diskripsi yang sesuai dengan teori Linguistic Universal, sehingga seorang anak mempunyai kesiapan secara fitrah 
mengembangkan pola-pola umum dalam nahwu. (Musthafa at-Thuny, 1993, hal.47-48)

\section{(2) Istima' Tinjauan Ilmu Ashwat (Fonology / علـم الاصـوات)}

Dalam pembahasannya lebih berorientasi pada unsur bunyi bahasa. Muhtar Umar A, 1991, 104 mengatakan bahwa suara merupakan unsur pembentuk bahasa (kalimat dan ungkapan), maka bahasa hanyalah serentetan bunyi suara yang berurutan. Dalam aspek ini pada dasarnya lebih menitik beratkan pada bagaimana membedakan antara bunyi yang satu dengan yang lainnya, maka Kamal Ibrahim Badry, 1981, 26) mengusulkan format membedakan bunyi yaitu: 


\begin{tabular}{|c|c|}
\hline (ذ) & ذهب \\
\hline ()) & رجال \\
\hline (j) & زهر \\
\hline (w) & سرير \\
\hline (ش) & شباك \\
\hline
\end{tabular}

\begin{tabular}{|l|l|}
\hline (ك) & كتاب| \\
\hline (J) & منائر \\
\hline (م) & (م) \\
\hline$(0)$ & \\
\hline
\end{tabular}

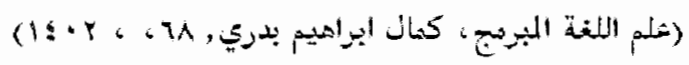

Aspek bunyi bahasa juga merupakan komponen yang berpengaruh dalam perkembangan bahasa. Menurut Abdul Madjid mengatakan dikatakan bahwa diantara unsur yang berpengaruh terhadap perkembangan bahasa antara lain berasal dari Tabi'at bahasa, tabi'at bunyi bahasa, tata bahasa, matannya, dan unsur- unsur lain yang berkaitan langsung dengan bahasa itu sendiri, hal itu bahwasanya unsur-unsur kebahasaan berkembang dan berpengaruh besar dalam perkembangan bahasa.(Abdul Madjid, 1983,hal.11).

\section{(3) Istima' Tinjauan Ilmu Al-Dalalah/Makna (علـــ/ الدلاـة/Semantic Unit)}

Para ahli bahasa dalam penggunaan istilah ini terdapat perbedaan, ada yang lebih suka menggunakan dengan istilah semantic unit yaitu istilah yang kami juga menggunakannya, diantara yang lain menggunakan istilah sememe yang istilah ini digunakan pertama kali oleh Adolf Noreen dari Swedia pada tahun 1908 M kemudian masuk ke AS oleh Bloomfield pada tahun $1926 \mathrm{M}$.

Nida tentang semantic unit mengklasifikannya kedalam 4 klasifikasi utama yaitu: Pertama, kata tunggal (الكليـة المفــدة), Kedua, Unitary Complek 
(تركيــ, Ketiga, Murfem Muttasil (bagian lebih keci dari kata), dan Keempat, Suara tunggal (bagian lebih dari morfim). Maka kalimat tunggal merupakan bagian terpenting dalam kajian ilmu ini. Sedangkan bidang umumnya dalam hal Tarkib yang berupa ungkapan-ungkapan yang tidak bisa dimengerti artinya secara sempurna dengan hanya melihat arti setiap kata dan menyusunnya yang lebih dikenal denga istilah Idiomatic (meliputi Idiom, Unitary complek, dan composite/composite expresseion) Maka secara diagram sebagai berikut:

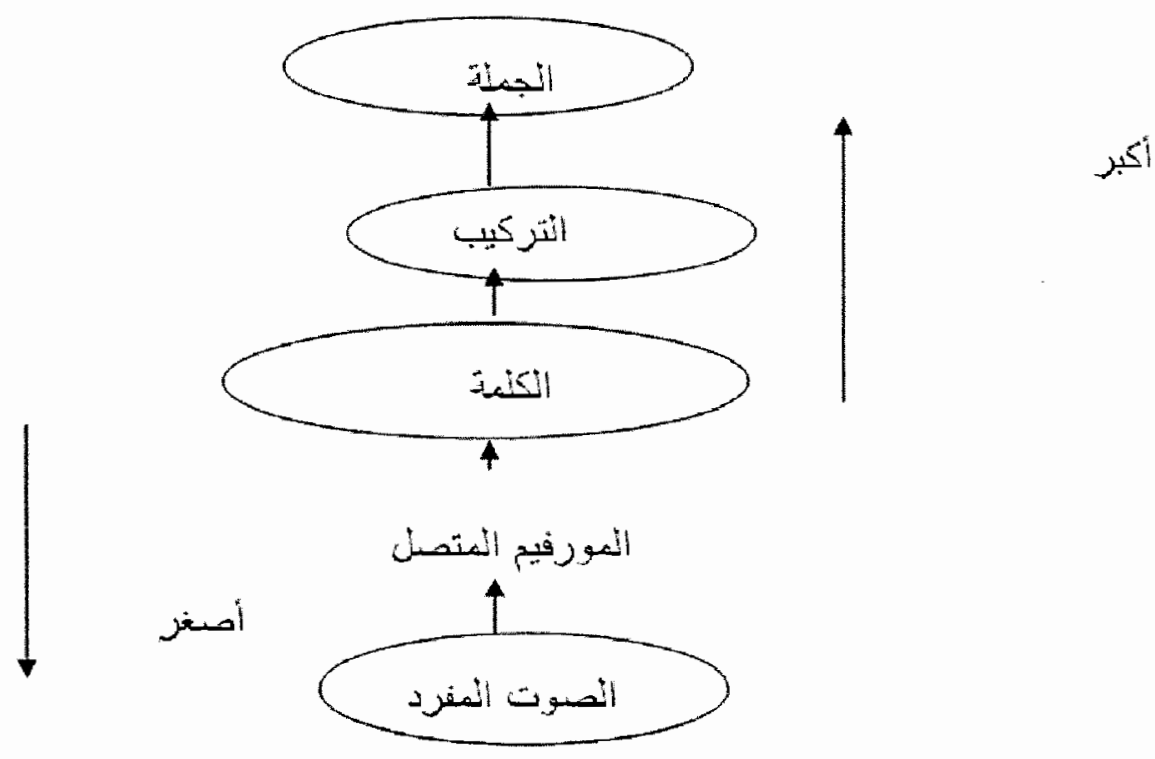

Umar, Ahmad Muhtar, 1982, hal. 32

Secara umum pembahasan ini berorientasi pada sisi makna baik makna leksikal maupun makna konteks, oleh sebab itu individu pembelajar bahasa dituntut mempunyai perasaan kebahasaan yang kuat.

Selain hal tersebut diatas semantic unit juga membahas tentang macam-macam makna sebuah kata dimana mukhtar umar mengemukakan 5 macam meliputi; Al-makna al-asasy / conceptual meaning, Al-ma'na alidlofy, Al-ma'na al-usluby, Al-ma'na al-nafsy, dan Al-ma'na al-Ikhay (Umar, Ahmad Muhtar, 1982, 195). 


\section{Tinjauan Teori Inovatif Transformatif Terhadap Surat Al- Waqi'ah Ayat 77-79}

Surat al-Waqi'ah ayat 77-79

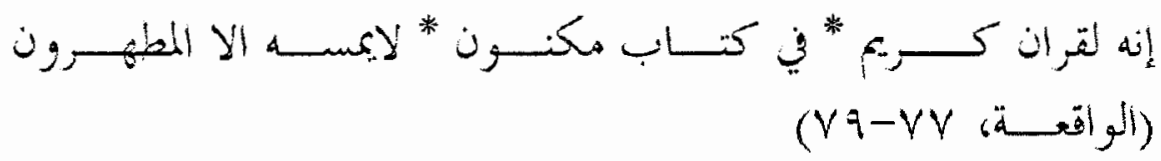

Sesungguhnya sumpah itu adalah sumpah yang sangat mulia *. Pada kitab yang terpelihara (lauhul mahfuzh) *. Tidak menyentuhnya kecuali orangorang yang disucikan *. (Q.S. 56, Ayat: 77-79)

Al-Maknun, menurut arti leksikal berarti al-mastur (tersimpan) seperti lafad $z$..............sebagaiman pendapat Ibnu abbas dengan arti al-lauh al- mahfudz, berbeda dengan Imam qatadah memberikan arti dengan almushaf dan al-maknun diartikan dengan al-mahfudz yaitu terjaga dari penggantian dan perubahan (Asyhabuny, Ayatul Ahkam,jilid II, 497). Dalam kata "Al-Maknun" perbedaan terlihat jelas dalam aspek Semantic Unit yaitu Perbedaan dalam memberikan arti Al-Maknun, perbicangan ini sangat menarik ketika dikaitkan dengan ilmu kalam. Dan hal ini menjadi perdebatan yang serius dikalangan ulama' ahli ilmu Kalam.

Al-muthahharun, menurut Aly al-shabuny berarti para malikat yang suci atau orang-orang yang suci dari hadats kecil dan besar yang bias menghalangi seseorang untuk melaksanakan sholat, maka menurut pendapat ini seseorang tidak boleh menyentuh al-qur'an kecuali dalam keadaan suci dari hadats kecil atau besar.

Ayat" la...... alla al-muthaharun", menurut pandangan ahli tata bahasa Arab huruf "La" pada kalimat "la yamasuhu" termasuk kategori huruf nafi (yang berarti "tidak"), akan tetapi harus diartikan nahi (yang berarti "jangan") dengan merujuk pada ayat "Azzani la.....Zaniyatan" (Asyhabuny, Ayatul Ahkam, 501). Disini terlihat ada keterkaitan antara ilmu tata bahasa Arab (Nahwu / Sharf) dan ilmu al- Dalalah / semantic unit. Ibnu Katsir memberikan arti "Al-Muthahharun" dengan arti terhindar dari hadats kecil atau besar , kemudian lebih jauh lagi berpendapat bahwa kata "la yamasuhu" 
termasuk kedalam jumlah khobariyah yang seharusnya diposisikan kedalam jumlah Thalabiyah, sedangkan mengartikan "al-Qur'an" dengan al-Mushaf sebagaimana yang ada sekarang ini.

Kata "Al-Muthahharun" jumhur ulama' melafalkannya dengan $\mathrm{Al}$ Muthahharun (double ha') berupa isim maf'ul dari kata "Thahhara", menurut Imam Nafi' seharusnya dilafalkan dengan "Al-mut harun" berasal dari kata "Athara", menurut Salman al-farisi melafalkan dengan "al-Mutathahharun" berasal dari kata "al-mutathihhirun" (Asyhabuny, Ayatul Ahkam,502).

Dalam perbincangan selanjutnya terjadi pada dlomir "hu" pada kata "la yamsuhu", yang menjadi perbincangan apakah dlomir "hu" merujuk paka kata "al-mushaf" atau pada kata "al-lauhu al-mahfudz", maka sebagai konsekwensi yang muncul adalah jika dlomir itu merujuk pada al-lauhu almahfudz, maka menyentuh al-qur'an tidak diharuskan berwudlu. Berbeda jikalau dlomir "hu" merujuk pada kata "Al-Mushaf", maka menyentuh alqur'an diharuskan berwudlu.

Sebagai perbincangan akhir dalam permasalahan ini Imam malik, Abu Hanifah, dan Imam Syafi'I menegaskan kepada generasinya agar berwudlu sebelum menyentuh al-Qur'an.

\section{E. Penutup}

Aspek-aspek tersebut diatas merupakan satu kesatuan yang saling terkait sehingga pendengar ujaran bahasa Arab dapat memahami dan menangkap isi pembicaraan secara utuh dan sempurna. Dan tulisan ini -sekaligus- menyatakan menolak terhadap pandangan yang mengatakan bahwa memahami teks bahasa Arab hanya semata-mata menggunakan berpegangan pada Ilmu Tata Bahasa Arab saja, atau juga menolak terhadap pandangan yang lebih menekankan pada penguasaan arti kata setiap mufradat (kosa kata).

Demikian tulisan ini, kami sangat mengharapkan kritik konsrtuktif dan saran demi perbaikan serta penyempurnaan tulisan ini. 


\section{DAFTAR PUSTAKA}

Al-Qur'an Dan Terjemahannya, Depag, C.V. Thoha Putra, Semarang, 1989 Abdul Madjid Sholah, Dkk, Ta'allumu Al-Lughah Al-Hayah Wa Ta'lymuha,Libanon, 1981

Asyabuny, Aly, Muhammad, Makkah, Tafsir Ayatul Ahkam, Harakah, Mustofa, Al-Shautyah Wa Al-Fonologya, Beirut,1998 Ibrahim Badry, Kamal, Ilmu Lughah Al-Mubarmaj,Riyadh, Percetakan Al. Mulk Ibnu Su’ud,1981

Madkur Ahmad, Ta'limu alistima', Daru Al-Ma'arif, Kairo, 1984, hal.6869).

Musthafa At-Thuny, 'Ilmu Al-Lughah Al Nafsy, Al-Haiah Al-Misriyah AlAmmah. Mesir, 1993

Syauqy Dhoif, Taysiru Al-Nahwi Al-Ta'limy Qadiman Wa Haditsan Ma'a Nahiji Tajdidihi, Daru Al-Ma'arif, Kairo, 1986

Umar, Ahmad Muhtar, Ilmu Al-Dalalah, Dar Al-Arubah, Cetakan Pertama, Kuwait, 1982

Wahid, Abdul, Al Wafi, 1al-Lughah Wa Al-Mujtama', Cet,Keempat, Riyadh, Penerbit 'Ukadh, 1983 